\title{
Passive Immunoneutralization of Endogenous Inhibin Increases Ovulation Rate in Miniature Shiba Goats
}

\author{
Mohamed S. MEDAN ${ }^{1,2)}$, Gen WATANABE ${ }^{1,4)}$, Yoshio NAGURA ${ }^{3)}$, \\ Hiroko KANAZAWA ${ }^{3)}$, Masaru FUJITA ${ }^{3)}$ and Kazuyoshi TAYA ${ }^{1,4)}$ \\ 1) Laboratory of Veterinary Physiology, Tokyo University of Agriculture and Technology, Tokyo \\ 183-8509, Japan, ${ }^{2)}$ Department of Theriogenology, Faculty of Veterinary Medicine, Suez \\ Canal University, Ismailia, Egypt, ${ }^{3)}$ National Livestock Breeding Center, Nagano Station, \\ Nagano 385-0007, ${ }^{4}$ Department of Basic Veterinary Science, United Graduate School of \\ Veterinary Sciences, Gifu University, Gifu 501-1193, Japan
}

\begin{abstract}
We reported previously that passive immunization against inhibin enhances follicular growth and increases the ovulation rate. However, the ovulation rate was not comparable to the number of follicles. Therefore, the aim of this study was to attempt to increase the ovulation rate by increasing the interval between inhibin immunization and $\mathrm{PGF}_{2 \alpha}$ injection. Five miniature Shiba goats were treated with $10 \mathrm{ml}$ inhibin antiserum (inhibin-AS) developed against [Tyro $\left.{ }^{30}\right]$-inhibin $\alpha(1-30)$. A control group $(n=5)$ was treated with normal goat serum. All animals were injected intramuscularly with $125 \mu \mathrm{g} \mathrm{PGF}_{2 \alpha} 72 \mathrm{~h}$ after treatment to induce estrus and ovulation. Blood samples were collected for hormonal assay and the ovulation rate was determined by laparotomy. In contrast to the control group, there was a significant increase in plasma concentrations of FSH in the immunized group. After luteolysis, plasma concentrations of estradiol-17 $\beta$ increased markedly to a preovulatory peak about 2 folds higher $(\mathrm{P}<0.01)$ than that of controls. In addition, the ovulation rate was greater in the immunized group $(14.4 \pm 2.2)$ than in the control group $(2.2 \pm 0.6)$, and the mean number of follicles $\geq$ $4 \mathrm{~mm}$ in diameter was $10.0 \pm 0.8$ in the inhibin-AS group compared with $2.4 \pm 0.3$ in control group. The present results demonstrate that immunoneutralization of endogenous inhibin increased FSH secretions in miniature shiba goats. The increased FSH secretion enhanced follicular growth and increased the ovulation rate. Additionally, increasing the interval between inhibin-AS and PGF $2 \alpha$ injections (to $72 \mathrm{~h}$ ) resulted in a greater ovulation rate compared with the previous protocol (48 h). Therefore, inhibin-AS treatment proved to be an effective alternative to exogenous gonadotropin methods for induction of superovulation in goats.
\end{abstract}

Key words: Inhibin, FSH, Ovulation rate, Miniature Shiba goats

(J. Reprod. Dev. 50: 705-710, 2004)

mmunoneutralization of endogenous inhibin selectively increases FSH secretion, providing evidence that inhibin is an important factor in the inhibitory regulation of FSH secretion in goats [1, 2]. Multiple ovulations have been induced successfully by passive immunoneutralization of

Accepted for publication: September 7, 2004

Correspondence: K. Taya (e-mail: taya@cc.tuat.ac.jp) endogenous inhibin in several species such as rats [3, 4], ewes [5-7], hamsters [8], cows [9, 10], mares [11], guinea pigs [12], mice [13, 14], and goats [2].

In previous studies, a combination of equine chorionic gonadotrophin (eCG) and human chorionic gonadotrophin (hCG) has been widely used to induce superovulation in goats. However, the long half-life of eCG interferes with normal 
fertilization and embryo development $[15,16]$, and repeated eCG treatments induced anti-eCG antibodies that clearly had negative effects on reproduction in goats [17]. This led us to establish a new protocol for superovulation in goats, and we succeeded in inducing superovulation in goats by using passive [2] and active [18] immunization against inhibin. However, in our previous passive immunization protocol for goats, the ovulation rate $(4.2 \pm 0.5)$ was not comparable to the greater number of follicles $(13.5 \pm 0.8)$ observed in the ovary at ovulation. Therefore, in the present study, we injected $\mathrm{PGF}_{2 \alpha} 72 \mathrm{~h}$ after treatment with inhibinAS (24 $\mathrm{h}$ later than the previous protocol) in an attempt to increase the ovulation rate. The present study aimed to improve the passive immunization protocol for induction of superovulation in goats.

\section{Materials and Methods}

\section{Experimental animals}

Ten mature miniature Shiba goats (Capra hircus), 1.5 to 3 years of age and weighing $28.0 \pm 1.5 \mathrm{~kg}$, housed under natural day-light and fed hay ad libitum were used in this study. Estrous cycles were synchronized with 2 injections of $125 \mu \mathrm{g}$ of a synthetic analogue of prostaglandin $\mathrm{F}_{2 \alpha}$ (Estrumate, Schering Plough Animal Health, New Jersey, USA) 11 days apart. Estrous behaviour was observed and checked with mature bucks. On day 10 of the estrous cycle animals were allocated to two groups: (1) control, treated with i.v. injection of $10 \mathrm{ml}$ normal goat serum $(n=5)$; and (2) inhibinimmunized, treated with i.v. injection of $10 \mathrm{ml}$ inhibin antiserum $(n=5)$. The time of injection of serum was defined as $0 \mathrm{~h}$. At $72 \mathrm{~h}$, all animals were injected intramuscularly with $125 \mu \mathrm{g} \mathrm{PGF}_{2 \alpha}$ to induce estrus and ovulation. Blood samples were collected at 6-h intervals from $24 \mathrm{~h}$ before until 144 $\mathrm{h}$ after treatment. For determination of LH surge, blood samples were collected every $2 \mathrm{~h}$ from 48 to $72 \mathrm{~h}$ after $\mathrm{PGF}_{2 \alpha}$ injection. Blood samples were collected from jugular venipuncture into heparinized Vacutainer tubes (Terumo Venoject II, Tokyo, Japan), and centrifuged at $1200 \mathrm{~g}$ for $15 \mathrm{~min}$ at $4 \mathrm{C}$. The plasma was separated and stored at -20 $\mathrm{C}$ until assayed for hormones.

\section{Determination of ovarian response}

The follicle populations and ovulation rate (ovulation rate was calculated from the number of corpora lutea) were determined one week after estrus by mid-ventral laparotomy. All animal procedures were completed in accordance with institutional animal care and use guidelines.

\section{Antisera}

The antiserum against inhibin used in this study was raised in ovariectomized goats to a synthetic peptide of the 1-30 amino acid sequence of the Nterminal of the $\alpha$-chain of porcine inhibin conjugated to rabbit serum albumins as described previously [1].

\section{Hormone analysis}

Plasma concentrations of FSH were measured by radioimmunoassay (RIA) system as described previously [1] by using NIDDK-antiovine FSH-1 (AFP-C5288113), NIDDK-FSH-I-1 (AFP5679C) for radioiodination, and NIDDK-oFSH-RP-1 as a reference standard. Plasma concentrations of LH were measured by RIA as described previously [19] by using antiovine LH (YM No. 18), NIDDK-oLH-I3 for radioiodination, and NIDDK-oLH-RP-24 as a reference standard. The intra- and inter-assay coefficients of variation were $9.8 \%$ and $12.2 \%$ for FSH and $5.5 \%$ and $6.3 \%$ for $\mathrm{LH}$, respectively. Plasma concentrations of estradiol-17 $\beta$ and progesterone were determined by a double antibody RIA system using ${ }^{125} \mathrm{I}$-labeled radioligands as described previously [20]. Antisera against estradiol-17 $\beta$ (GDN 244) and progesterone (GDN 337) were kindly provided by Dr. G.D. Niswender (Animal Production and Biotechnology, Colorado state University, Fort Collins, Co. USA). The intra- and inter-assay coefficients of variation were $5.9 \%$ and $7.2 \%$ for estradiol $-17 \beta$ and $8.0 \%$ and $9.4 \%$ for progesterone, respectively.

\section{Statistical analysis}

Data are presented as means $( \pm$ SEM). Student's $t$-test was used to compare between the two groups using the SAS computer package [21]. Values were considered statistically different when $P<0.05$.

\section{Results}

\section{Plasma concentrations of FSH and LH}

In the control group, plasma concentrations of FSH did not significantly change after injection of 

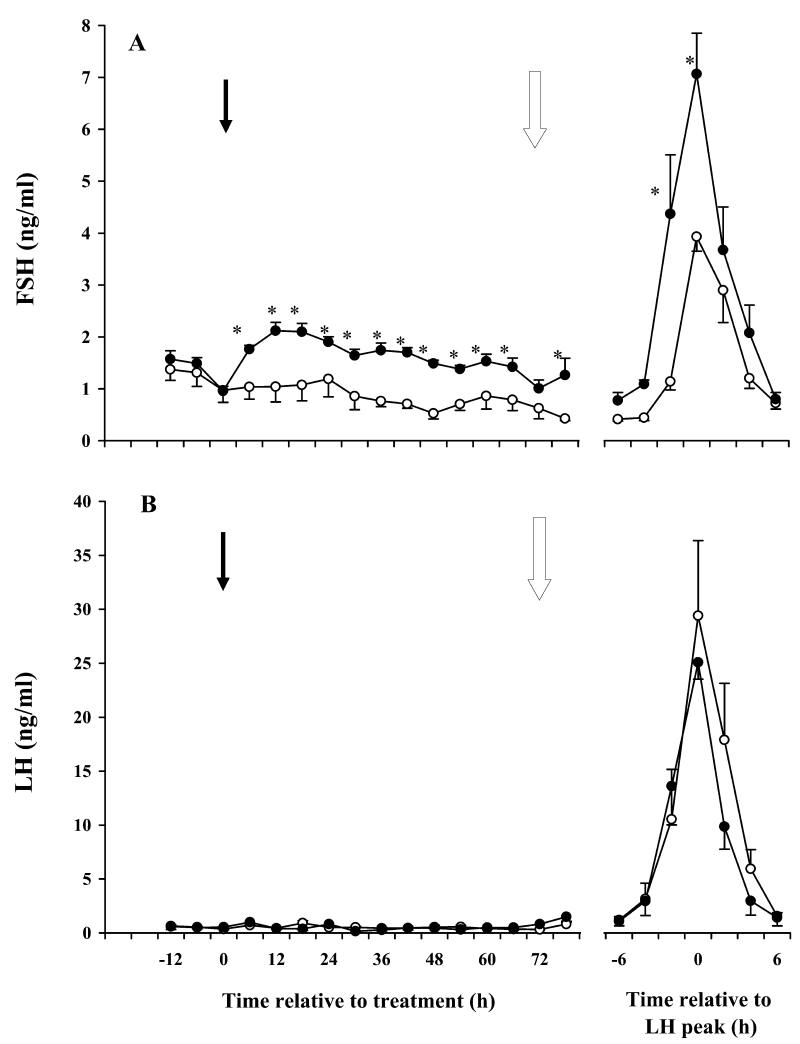

Fig. 1. Changes in plasma concentrations of FSH (A) and LH (B) in miniature shiba goats after treatment with inhibin-AS (closed circle) or control serum (open circle). Black arrows indicate time of serum injection and white arrows indicate time of PG injection. Values are mean \pm SEM of five animals. ${ }^{*}(P<0.05)$ versus control values. normal goat serum during the period before FSH surge. In contrast, treatment with the inhibin antiserum resulted in a significant $(P<0.05)$ increase in plasma concentrations of FSH compared with control values within $6 \mathrm{~h}$ after treatment (Fig. 1A). In addition, the preovulatory FSH peak in the inhibin immunized group was significantly higher than in the control group. Moreover, the time interval between the $\mathrm{PGF}_{2 \alpha}$ injection and the preovulatory gonadotropin surge tended to be shorter $(P=0.07)$ in the immunized group than in the control group (Table 1). On the other hand, there was no significant difference between the immunized and control groups in LH levels (Fig. 1B).

\section{Plasma concentrations of estradiol-17 $\beta$ and progesterone}

The plasma concentration of estradiol- $17 \beta$ is shown in Fig. 2A. In control animals, plasma concentrations of estradiol-17 $\beta$ increased after the $\mathrm{PGF}_{2 \alpha}$ injection and reached a peak $(51.3 \pm 12.3 \mathrm{pg} /$ $\mathrm{ml}$ ) level within $48 \mathrm{~h}$. However, treatment with inhibin antiserum induced a rapid and marked increase in plasma estradiol- $17 \beta$ which reached a peak level $(96.5 \pm 24.5 \mathrm{pg} / \mathrm{ml})$ earlier than the control animals. On the other hand, passive immunization against inhibin had no effect on plasma progesterone concentrations and injection of $\mathrm{PGF}_{2 \alpha} 72 \mathrm{~h}$ after inhibin antiserum or normal goat serum treatment resulted in a sharp decline in progesterone concentrations in both immunized

Table 1. Effect of immunoneutralization of endogenous inhibin on estrus and ovarian response in miniature Shiba goats

\begin{tabular}{lcc}
\hline Item & Control group & Immunized group \\
\hline Number of treated goats & 5 & 5 \\
Number of goats detected in estrus $^{\mathrm{a}}$ & 5 & 5 \\
Number of goats ovulating $^{\text {Interval to estrus }}{ }^{\mathrm{b}}(\mathrm{h})$ & 5 & 5 \\
Interval to preovulatory gonadotropin surge $^{\mathrm{c}}(\mathrm{h})$ & $57.6 \pm 4.5$ & $48.0 \pm 3.8$ \\
Ovulation rate $^{\mathrm{d}}$ & $65.6 \pm 5.0$ & $53.6 \pm 2.8$ \\
Mean number of follicles $\geq 4 \mathrm{~mm}$ in diameter $^{\mathrm{e}}$ & $2.2 \pm 0.6$ & $14.4 \pm 2.2^{* *}$ \\
Ovarian activity $^{\mathrm{f}}$ & $2.4 \pm 0.3$ & $10.0 \pm 0.8^{* *}$ \\
\hline
\end{tabular}

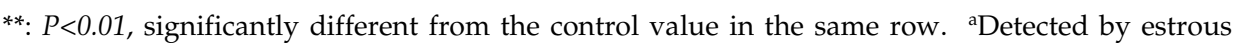
observation and mature bucks. ${ }^{b}$ Hours from $\mathrm{PGF}_{2 \alpha}$ injection to onset of estrus. ${ }^{\mathrm{c} H o u r s}$ from $\mathrm{PGF}_{2 \alpha}$ injection to preovulatory FSH and LH surges. ${ }^{\mathrm{d}} \mathrm{By}$ direct observation and counting corpora lutea at laparotomy. ${ }^{\mathrm{e}}$ By direct observation and counting follicles at laparotomy. ${ }^{\mathrm{f}}$ Number of follicles and corporal lutea. 
and control groups (Fig. 2 B).

\section{Ovulation rate and number of follicles}

In the immunized group, the number of corpora lutea was significantly $(P<0.01)$ higher than in the control group as determined by direct observation one week after estrus. Moreover, the number of unovulated follicles $\geq 4 \mathrm{~mm}$ in diameter was significantly $(P<0.01)$ greater in the immunized group. The ovarian activity, number of follicles and corporal lutea, of the immunized group was found to be 5 times greater than that of the control group (Table 1).

\section{Discussion}

Immunoneutralization of endogenous inhibin in cyclic miniature Shiba goats resulted in an increase in plasma concentrations of FSH and ovulation rate. The preovulatory gonadotropin surge occurred earlier than in the control group. This may be attributable to the earlier peak in estradiol$17 \beta$ in the immunized goats which in turn induced $\mathrm{GnRH}$ release from the hypothalamus and release of LH and FSH. The FSH-mediated mechanism of action of inhibin immunization on the ovulation rate in the present study is in agreement with our previous results [2]. Furthermore, a reciprocal relationship between circulating FSH and inhibin levels during the estrous cycle has been reported in goats [22], suggesting that inhibin secreted from the ovary plays an important role as a regulator of FSH secretion. The rise in FSH concentration seen following immunization stimulated multiple growth of follicles and increased the ovulation rate. However, the ovulation rate in the present study was greater than that which we previously reported in goats [2]. The greater ovulation rate seen in the present study might be attributable to the injection of $\mathrm{PGF}_{2 \alpha} 72 \mathrm{~h}$ after inhibin-AS treatment $(24 \mathrm{~h}$ later than the previous protocol) allowing more time for follicular growth and differentiation.

Previous results obtained from active immunization [23] or repeated injections of inhibin antiserum [24, 25] suggested the possibility that ovarian response to inhibin immunization is not only mediated by the rise in circulating FSH levels but also by the direct effect of immunization on follicular growth. Hennies et al. [26] reported an
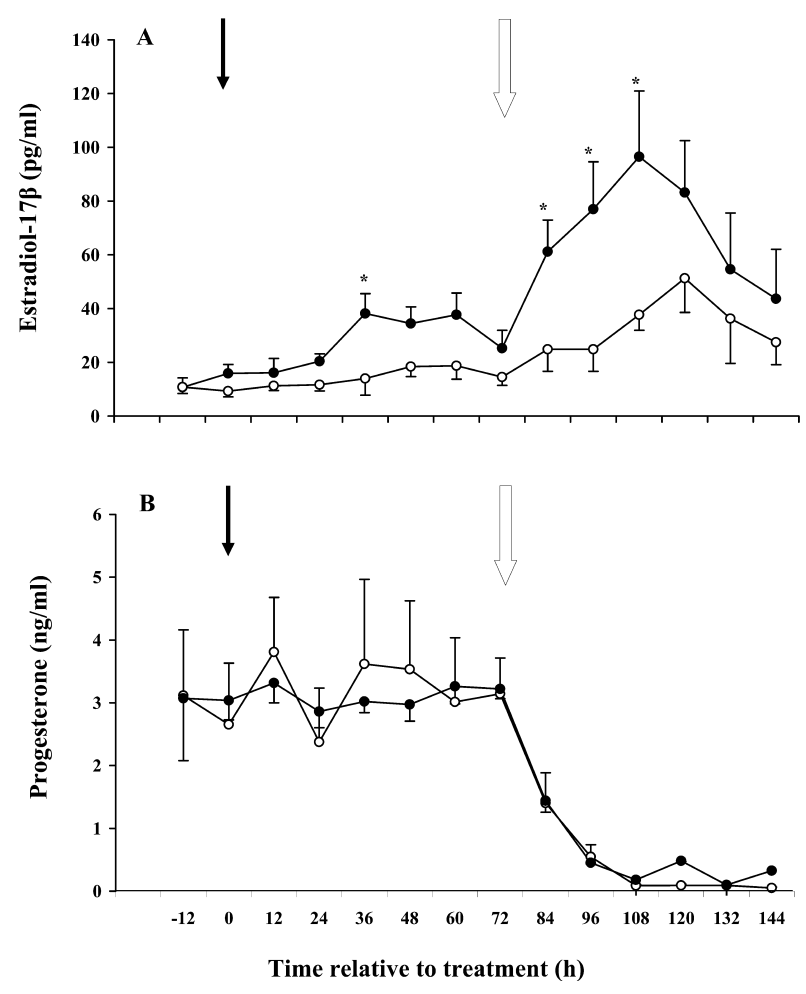

Fig. 2. Changes in plasma concentrations of estradiol-17 $\beta$ (A) and progesterone (B) in miniature Shiba goats after treatment with inhibin-AS (closed circle) or control serum (open circle). Black arrows indicate time of serum injection and white arrows indicate time of PG injection. Values are mean \pm SEM of five animals. ${ }^{*}(P<0.05)$ versus control values.

increase in ovulation rate in goats actively immunized against inhibin without a marked increase in FSH. In goats treated with inhibin antiserum, there was a marked rise in estradiol- $17 \beta$. This rise in estradiol- $17 \beta$ may reflect an increased number of growing follicles. Therefore, immunoneutralization of endogenous inhibin enhances follicular development and in turn secretion of estradiol- $17 \beta$ from the ovarian follicles. Similar results were recorded in cattle [10, 27].

It is well known that repeated use of eCG for inducing superovulation in goats results in diverse effects because of the formation of anti-eCG antibodies [17]. Moreover, a higher incidence of premature corpus luteum regression in eCGstimulated versus FSH-superovulated goats has been recorded [15, 28, 29]. Therefore, passive immunization against inhibin which selectively increases FSH secretion resulting in a dramatic increase in the ovulation rate may be a suitable and 
simple alternative to eCG for inducing superovulation in goats.

In conclusion, the present study demonstrated that passive immunization against inhibin increased FSH secretions. In addition, injection of $\mathrm{PGF}_{2 \alpha} 72 \mathrm{~h}$ after inhibin immunization improved the superovulation response resulting in a greater ovulation rate. Therefore, neutralization of inhibin bioactivity followed by $\mathrm{PGF}_{2 \alpha}$ injection can be used as an alternative method for inducing superovulation in goats.

\section{Acknowledgements}

We are grateful to Dr AF Parlow (National Institute of Diabetes and Digestive and Kidney
Diseases, Beltsville, MD, U.S.A.) for providing RIA materials for ovine FSH and LH, Dr G D Niswender (Animal Reproduction and Biotechnology Laboratory, Colorado State University, Fort Collins, CO, U.S.A.) for providing antisera to estradiol-17 $\beta$ (GDN 244) and progesterone (GDN 337) and Dr Y Mori (University of Tokyo, Bunkyo-ku, Tokyo, Japan) for antiserum to ovine LH (YM-18). This work was supported in part by the Ito Foundation and the Japan Livestock Technology Association, a Grant-in-Aid for Scientific Research (The 21st Century Center of Excellence Program, E-1) from the Ministry of Education, Culture, Sports, Science and Technology of Japan and a Grant-in-Aid for Scientific Research (No. 03338) from the Japan Society for the Promotion of Science.

\section{References}

1. Araki K, Arai K, Watanabe G, Taya K. Involvement of inhibin in the regulation of follicle-stimulating hormone secretion in the young adult male shiba goat. J Andrology 2000; 21: 558-565.

2. Medan MS, Watanabe G, Sasaki K, Nagura $Y$, Sakaime H, Fujita M, Sharawy S, Taya K. Effects of passive immunization of goats against inhibin on follicular development, hormone profile and ovulation rate. Reproduction 2003; 125: 751-757.

3. Rivier C, Vale W. Immunization of endogenous inhibin modifies hormone secretion and ovulation rate in the rat. Endocrinol 1989; 125: 152-157.

4. Ishigame $\mathbf{H}$, Medan MS, Watanabe G, Shi Z, Kishi H, Arai KY, Taya K. A new alternative method for superovulation passive immunization against inhibin in adult rats. Biol Reprod 2004; 71: 236-243.

5. Wheaton JE, Carlson KM, Kusina NT. Active and passive immunoneatralization of inhibin increases follicle-stimulating hormone levels and ovulation rate in ewes. Biol Reprod 1992; 47: 361-367.

6. Wheaton JE, Thomas DL, Kusina T, Gottfrendson RG, Meyer RL. Effects of passive immunization against inhibin-peptide on secretion of folliclestimulating hormone and ovulation rate in ewes carrying the Booroola fecundity gene. Biol Reprod 1996; 55: 1351-1355.

7. Kusina NT, Meyer RL, Carlson KM, Wheaton JE. Effects of passive immunization of ewes against an inhibin-peptide on gonadotropin levels, ovulation rate, and prolificacy. Biol Reprod 1995; 52: 878-884.

8. Kishi H, Okada T, Otsuka M, Watanabe G, Taya K, Sasamoto S. Induction of superovulation by immunoneutralization of endogenous inhibin through the increase in the secretion of follicle stimulating hormone in the cyclic golden hamster. $J$ Endocrinol 1996; 151: 65-75.

9. Akagi S, Kaneko H, Nakanishi Y, Takedomi T, Watanabe G, Taya K. Ovarian response and FSH profile in cows following injection of various doses of inhibin antiserum. J Vet Med Sci 1997; 59: 1129_ 1135.

10. Takedomi T, Kaneko H, Aoyagi Y, Konishi K, Kishi H, Watanabe G, Taya K. Effects of passive immunization against inhibin on ovulation rate and embryo recovery in Holstein heifers. Theriogenology 1997; 47: 1507-1518.

11. Nambo $\mathbf{Y}$, Kaneko $H$, Nagat $S$, Oikawa $M$, Yoshihara T, Nagamine N, Watanabe G, Taya K. Effect of passive immunization against inhibin on FSH secretion, folliculogenesis and ovulation rate during the follicular phase of estrous cycle in mares. Theriogenology 1998; 50: 545-557.

12. Shi F, Mochida K, Suzuki O, Mateuda J, Ogura A, Ozawa M, Watanabe G, Suzuki A, Taya K. Ovarian localization of immunoglobulin $\mathrm{G}$ and inhibin $\alpha$ subunit in guinea pigs after passive immunization against the inhibin $\alpha$ subunit. J Reprod Dev 2000; 46: 293-299.

13. Wang H, Herath CB, Xia G, Watnabe G, Taya K. Superovulation, fertilization and in vitro embryo development in mice after administration of an inhibin-neutralizing antiserum. Reproduction 2001; 122: 809-816.

14. Medan MS, Wang H, Watanabe G, Suzuki AK, Taya K. Immunization against endogenous inhibin increases normal oocyte/embryo production in 
adult mice. Endocrine 2004; 24: 115-119.

15. Armstrong DT, Pfitzner AP, Warnes GM, Seamark RF. Superovulation treatments and embryo transfer in Angora goats. J Reprod Fertil 1983; 67: 403-410.

16. Ertzeid G, Storeng R, Lyberg T. Treatment with gonadotropins impaired implantation and fetal development in mice. J Assis Reprod Genet 1993; 10: 286-291.

17. Roy F, Maurel M, Combes B, Vaiman D, Cribiu E, Lantier I, Pobel T, Deletang F, Combarnous Y, Guillou F. The negative effect of repeated equine chorionic gonadotropin treatment on subsequent fertility in Alpine goats is due to a humoral immune response involving the major histocompatibility complex. Biol Reprod. 1999; 60: 805-813.

18. Medan MS, Watanabe G, Sasaki K, Nagura Y, Sakaime H, Fujita M, Sharawy S, Taya K. Ovarian and hormonal response of female goats to active immunization against inhibin. J Endocrinol 2003; 177: 287-294.

19. Mori Y, Kano Y. Changes in plasma concentrations of $\mathrm{LH}$, progesterone and estradiol in relation to the occurrence of luteolysis, estrus and time of ovulation in shiba goats (Capra hircus). J Reprod Fertil 1984; 72: 223-230.

20. Taya K, Watanabe G, Sasamoto S. Radioimmunoassay for progesterone, testosterone and estradiol $17 \beta$ using ${ }^{125}$ I-iodohistamine radiolligands. Jap J Anim Reprod 1985; 31: 186-197.

21. SAS. Statistics, version 6.11. Cary, NC: SAS Institute Inc; 1987.

22. Medan MS, Watanabe G, Sasaki K, Sharawy S, Groome NP, Taya K. Ovarian dynamics and their associations with peripheral concentrations of gonadotropins, ovarian steroids, and inhibin during the estrous cycle in goats. Biol Reprod 2003; 69: 57-63.

23. Bleach ECL, Muttukrishna S, Cunningham FJ, Knight PG, Glencross RG. Effect of inhibin immunization using different synthetic peptide fragments of the bovine $\alpha c$-subunit on plasma antiinhibin titre, plasma FSH concentrations and the incidence of multiple ovulation in heifers. Anim Reprod Sci 1996; 41: 1-12.

24. Campbell BK, Scaramuzzi RJ. Effect of acute immunoneutralization of inhibin in ewes during the late luteal phase of the estrous cycle on ovarian hormone secretion and follicular development during the subsequent follicular phase. J Reprod Fertil 1995; 104: 337-345.

25. Campbell BK, Gordon BM, Tsonis CG, Scaramuzzi RJ. The effect of acute immunoneutralization of inhibin in ewes during the early luteal phase of estrous cycle on ovarian hormone secretion and follicular development. $J$ Endocrinol 1995; 145: 479-490.

26. Hennies M, Voglmayr JK, Dietrich E, Stollmann M, Moeller R, Holtz W. Hormonal response of female goats to active immunization against a recombinant human inhibin $\alpha$-subunit, and establishment of an enzyme-linked immunosorbent assay for caprine follicle-stimulating hormone. Reprod Domest Anim 2001; 36: 65-71.

27. Kaneko H, Nakanishi Y, Akagi S, Taya K, Watanabe G, Sasamoto $S$, Hasegawa $Y$. Immunoneutralization of inhibin and estradiol during the follicular phase of the estrus cycle in cows. Biol Reprod 1995; 53: 931-939.

28. Rosnina $\mathbf{Y}$, Jainudeen MR, Nihayah $\mathbf{M}$. Superovulation and egg recovery in goats in the tropics. Vet Rec 1992; 130: 97-99.

29. Riesenberg S, Meinecke-Tillmann S, Meinecke B. Ultrasonic survey of follicular development following superovulation with a single application of pFSH, eCG of hMG in goats. Small Rumin Res 2001; 40: 83-93. 